Sir - Your editorial "Dangers of publication by press conference" represents an excellent opportunity for open discussion of the peer-review process and how best to present scientific results to the public (Nature 393, 397; 1998). We also appreciate the compliment that the US space agency NASA has played an important role in increasing public interest in science.

You argued that public release of science results should occur only after peer review by journals. Without it, journalists may be unable to do justice to the story, and perhaps "the public will more often be faced with sensational and triumphant stories that subsequently prove to have been false". You concluded that NASA risks "undermining the respect for objectivity on which the public support for science ultimately rests". This narrow conclusion gives short shrift to public interest and the skills of the media.

NASA's charter requires the agency to disseminate as widely as possible the results of its publicly funded research. In the process, we must and do scrupulously safeguard our scientific credibility through strong attention to the peer-review process. Most of NASA's press briefings and press releases feature peer-reviewed results.

However, the benefits of having a larger vision are evident in many recent examples of near real-time science being presented to the people who've paid for it. Consider public awareness and excitement about science spurred by announcements of possible subsurface oceans on Europa and ice on the Moon, a glorious image of the Eagle Nebula, and breaking news such as comet Shoemaker-Levy 9 and Mars Pathfinder. There is little evidence of damage to public support for science in the wake of these often tentative findings indeed, quite the opposite.

When a NASA-funded researcher chooses to submit a paper at a scientific meeting before journal publication — as with Susan Terebey's possible extrasolar planet - we consider its merits on a caseby-case basis. Usually, the results are scrutinized intently by scientists independent of NASA before we decide to release the results, which Nature acknowledged constitutes a form of peer review. My office turns down four or five interesting scientific results for every one that we decide to present publicly.

In subsequent media activities, we strongly underscore the preliminary status of the results, and the need for further observations. We work hard to ensure the story is told correctly. This message was clearly received during the press briefing on Terebey's research, as every one of the dozens of press reports that we saw included the proper caveats. Journalists were indeed able to do justice to the story and, in addition, probably did more to educate the public about the scientific process than any amount of journal editorializing ever could.

The tax-paying public is entitled to receive scientific results expeditiously in simple, understandable language. Nonscientists enjoy participating in the excitement and adventure of science - it may be preliminary and uncertain, but letting them participate in the progress of science can only be beneficial.

Finally, if the so-called "blob" in the image Terebey obtained is later proven not to be a planet, NASA will endeavour to be the first to announce it. We trust the public's common sense and its ability to understand that progress is not made without some missteps. Based on the NASA values of openness and honesty, we are confident in the correctness of our philosophy. Edward J. Weiler (Scientific Director) The Astronomical Search for Origins and Planetary Systems, Code S, NASA Headquarters, Washington DC 20546, USA

\section{Biotech battlelines}

Sir - When the Swiss people voted in the referendum of 7 June against the proposal to impose restrictions on genetic engineering, they signalled that they had decided against economic and scientific isolation from the rest of the world. But how was it possible that the fate of the rational world of science was decided by a war of emotions?

At the beginning of the referendum campaign, proponents and opponents of genetic engineering alike seized powerful images of human and animal suffering to rally the public behind their banners. Images of hospital patients were used by biotechnology proponents to remind the public that a ban would inflict a heavy price on those suffering from severe diseases and dependent upon state-of-the-art medical treatments. In 1996, 10 years after the Chernobyl explosion, those in favour of the ban circulated a portrait of a child born without eyes, with the words: "No one can predict the damages (from technology), as was the case for Chernobyl. We do not want a genetic catastrophe!"

As the campaign progressed, there was a shift in tactics on both sides. Those against the ban realized that complex scientific and moral considerations could be communicated to the public by emphasizing the importance of biotechnology to medical research, diagnostics and treatment. Proponents of the ban abandoned striking visual images, accentuating instead broader issues such as the dignity of creation and the purported ecological impacts of genetically modified crops.

The campaigning appears to have obeyed the principle revealed by the Eurobarometer survey of attitudes to biotechnology (Nature 387, 845-847; 1997). While people were willing to accept some risk as long as there was a perception of usefulness, the presence of moral doubts acted as a powerful veto by overwhelming all other considerations, including usefulness and risk.

The Eurobarometer study also demonstrated that, of the biotechnology applications it surveyed, genetic screening and medicines obtained the highest ratings for usefulness and moral acceptability, with a positive evaluation of risk. Crop plants were also evaluated positively for usefulness and moral acceptability, but the balance of risk was seen as negative. The authors of the study concluded that the technically based reassurances of regulators are unlikely to alleviate public concern about the acceptability of certain applications of biotechnology. The moral and political dimensions of risk are missing from the objective risk assessment framework that is usually applied to making cogent decisions about new technologies.

What we have seen in Switzerland is that the rational and analytical approach of science is no longer consistent with other world views. The era of objective, value-free science in an ivory tower is coming to a close. Scientists can no longer afford to ignore the social framework within which their research is performed. During the referendum campaign, scientists were concerned about the possibility of losing an important research tool — transgenic animals. It was the seriousness of this threat that drew them into the public spotlight to explain the importance of their work.

By choosing not to isolate themselves even further, the Swiss have recognized that science, when guided by evidence, can transcend linguistic and cultural barriers. This aspect of science serves the egalitarian ideals of modern, pluralistic societies in which all citizens can expect to exercise their right to vote.

Othmar Käppeli \& Lillian Auberson Biosafety Research and Assessment of Technology Impacts, Swiss Priority Programme, Biotechnology, Swiss National Science Foundation, Clarastrasse 13, CH-4058 Basel, Switzerland 